\title{
SISTEM PEMANTAUAN GETARAN PADA JALUR SOFT TRACK SECARA ONLINE
}

\author{
Erna Kusuma Wati ${ }^{1}$, Hari Hadi $S^{2}$, Ayu Maharani ${ }^{3}$, Fraska Anagga ${ }^{4}$ \\ Teknik Fisika, Universitas Nasional \\ ernakusuma.w@gmail.com
}

Submitted November 12, 2020; Revised December 1, 2020; Accepted December 2, 2020

\begin{abstract}
Abstrak
Seiring dengan pengembangan infrastuktur jalan tol, perlu kita antisipasi dan melakukan pemantauan efek yang ditimbulkannya, terutama bagi penduduk yang tinggal disekitar jalur tol. Efek getaran yang ditimbulkan oleh lalu lalang kendaraan dapat mengganggu kesehatan penduduk, jika melewati Batas Ambang Maksimal. Berdasarkan hal tersebut, dlama penelitian ini akan merancang alat ukur getaran yang dapat dipantau secara online getaran (percepatan) tersebut. Alat ukur getaran telah dirancang dengan menggunakan sensor accelerometer MMA7361, Pengiriman data dilakukan secara online menggunakan modul WiFi ESP8266 dan menggunakan sumber WiFi hotspot portable dari telepon selular. Pengukuran dilakukan selama sekitar 30 menit di tepi ruas jalan tol Jakarta-Serpong tepatnya di Km-11. Dengan menggunakan 4 buah sensor pengukuran getaran maka dilakukan variasi jarak sensor terhadap ruas jalan tol, jarak masing-masing antar sensor adalah sejauh 3 meter. Hasil pengukuran dan pengujian terhadap getaran kendaraan yang melintas di jalan tol sepongJakarta pada keempat sensor menunjukkan nilai percepatan $<0,45 \mathrm{~m} / \mathrm{s}^{2}$. Hasil pengukuran terhadap getaran kendaraan yang melintas di jalan tol Jakarta-Serpong Km 11 menunjukkan nilai percepatan yang dihasilkan adalah $<0,45 \mathrm{~m} / \mathrm{s}^{2}$. berdasarkan tingkat resiko terhadap paparan getaran bagi kesehatan nilai percepatan tersebut berada dalam kategori rendah sehingga jarak jalur tol berada pada zona aman bagi kesehatan penduduk disekitar
\end{abstract}

Kata Kunci : soft track, accelerometer, MMA 7361, paparan getaran

\begin{abstract}
Along with the development of toll road infrastructure, we need to anticipate and monitor the effects it causes, especially for residents living around toll roads. The impact of vibrations caused by passing vehicles can disturb the health of the population if it crosses the Maximum Threshold. Based on this, during this research, we will design a vibration measuring device that can be monitored online by the vibration (acceleration). The vibration meter has been designed using the MMA7361 accelerometer sensor. Data transmission is carried out online using the ESP8266 WiFi module and using a portable WiFi hotspot source from a cellular phone. The measurement was carried out for about 30 minutes at the edge of the Jakarta-Serpong toll road, precisely at Km-11. By using four vibration measurement sensors, the sensor distance variations are carried out on toll roads, the distance between each sensor is as far as 3 meters. The results of measurement and testing of vehicle vibrations passing on the Sepong-Jakarta toll road on the four sensors show an acceleration value of $<0.45 \mathrm{~m} / \mathrm{s}^{2}$. The measurement results of the vibration of vehicles passing on the Jakarta-Serpong Km 11 toll roadshow that the resulting acceleration value is $<0.45 \mathrm{~m} / \mathrm{s}^{2}$. Based on the level of risk of exposure to vibration for health, the acceleration value is in a low category so that the toll lane distance is in a safe zone for the health of the surrounding population.
\end{abstract}

Key Words : soft track, accelerometer, MMA 7361

\section{PENDAHULUAN}

Jalan tol merupakan infrastruktur yang sedang berkembang saat ini untuk memudahkan dalam sarana transportasi dalam kota, maupun lintas provinsi. Sehingg perlu kita antisipasi dan melakukan pemantauan efek yang ditimbulkannya, terutama bagi penduduk 
yang tinggal disekitar jalur tol [1]. Efek getaran yang ditimbulkan oleh lalu lalang kendaraan dapat mengganggu kesehatan penduduk, jika melewati Batas Ambang Maksimal [2] .

Berdasarkan latar belakang tersebut, maka pada penelitian akan dilakukan perancangan dan pengukuran mengenai besarnya pengaruh percepatan getaran yang ditimbulkan oleh kendaraan bermotor disekitar tol [3] dengan menggunakan sensor getar accelerometer MMA7361. Penelitian ini juga merupakan pengembangan penelitian yang dilakukan dalam pemantauan getaran pada jalur kereta api hard track [4]. Pengukuran dilakukan berdasarkan pada kendaraan yang melintas dengan membawa muatan yang berat dan ringan disertai kecepatan yang tinggi, namun tepatnya berapa kecepatan dan berat yang sebenarnya tidak diketahui. Rencana pengukuran akan dilakukan pada area tepi bahu jalan tol yang terletak sekitar $3 \mathrm{~m}$ dari as lajur lambat. Pengiriman data akan dilakukan secara online menggunakan modul wifi ESP 8266 dan web server sebagai penampil data sehingga data hasil pengukuran dapat dipantau secara jarak jauh. Penyelidikan tanah tidak dilakukan dan hanya berlaku pada daerah penampang jalan tol yang direncanakan.

\section{METODE PENELITIAN}

Pengambilan data dilakukan di Jl. Tol Jakarta-Serpong KM.11. Pengukuran dilakukan pada jarak paparan terdampak dan besarnya amplitudo getaran pada tanah akibat sumber getar yang berasal dari jalan Tol. Kendaraan sebagai sumber getaran, direkam level getarannya melalui beberapa accelerometer yang berjarak masingmasing $3 \mathrm{~m}$ seperti Gambar 1 berikut

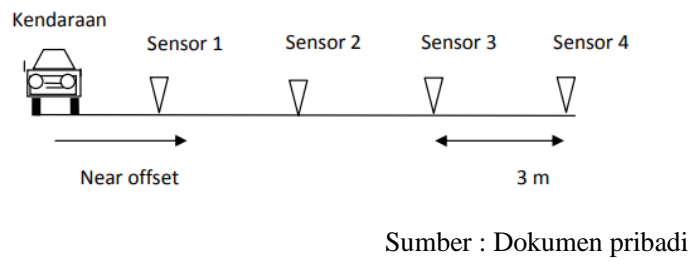

Gambar 1. Variasi Jarak pada Empat Buah Sensor saat Pengukuran

Skema perancangan sistem dalam penelitian yang ingin dibangun ditunjukkan pada Gambar 2. Parameter input yang berupa getaran akan terdeteksi oleh masing-masing sensor accelerometer.

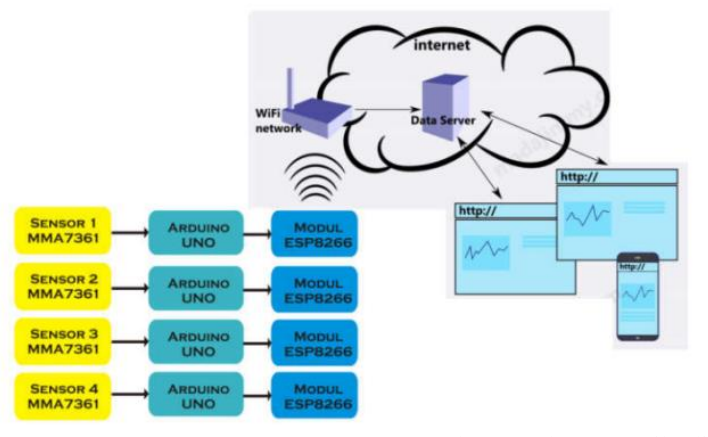

Sumber : Dokumen pribadi

\section{Gambar 2. Diagram Blok Sistem Pengukuran Getaran}

Pada Gambar 2 ditunjukkan skema diagram blok sistem pemantauan getaran jalan tol menggunakan sensor accelerometer. Sensor accelerometer yang digunakan sebanyak 4 buah, setiap sensor accelerometer MMA7361 mengirimkan data hasil pengukuran kepada mikrokontroler Arduino Uno [5]. Rancang bangun sistem pemantau getaran di jalan tol menggunakan sensor accelerometer ini terdiri dari beberapa bagian utama yang sesuai dengan blok diagram pada Gambar 2 Blok diagram sistem terdiri dari sensor accelerometer MMA7361, Arduino Uno, dan PC. Perncangan hardware dalam penelitian ini ditunjukkan di Gambar 3 merupakan wiring diagram rangkaian keseluruhan sistem pemantau getaran. 


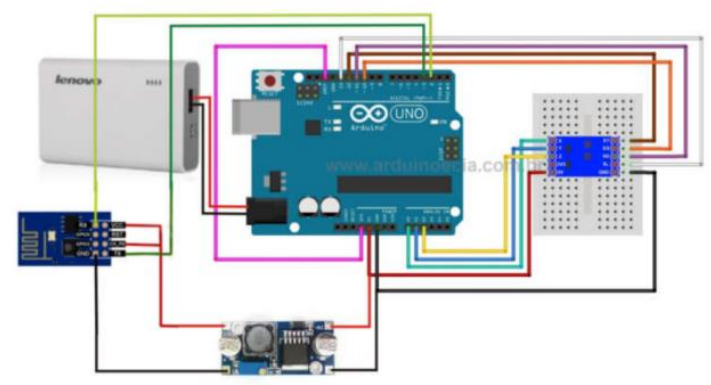

Sumber : Dokumen pribadi

\section{Gambar 3. Rangkaian Elektronik} Keseluruhan sistem Pemantau Getaran

Objek yang akan diukur adalah getaran yang diakibatkan dari kendaraan bermotor yang melintas di jalan tol. Data yang telah diterima Arduino kemudian oleh modul ESP 8266 dikirim ke database MySQL melalui server yang dapat diakses menggunakan web. Hasil pemantaun kemudian ditampilkan real time secara online pada web server dan dapat diunduh ke dalam bentuk Microsoft excel.

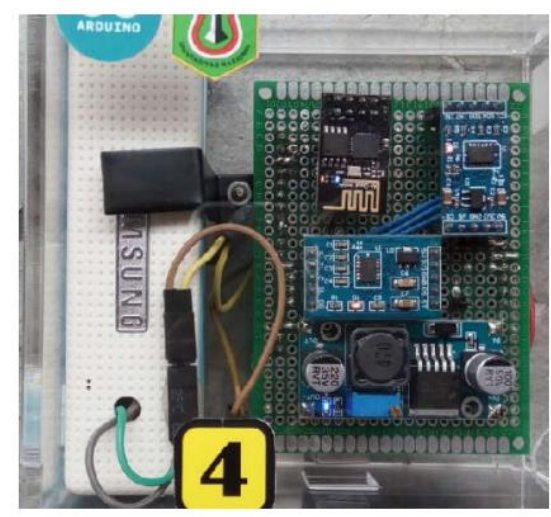

Sumber : Dokumen pribadi

\section{Gambar 4. Rangkaian Shield Controller Arduino}

Untuk perancangan software dalam penelitian ini, secara detail akan ditampilkan dalam diagram alir berikut ini:

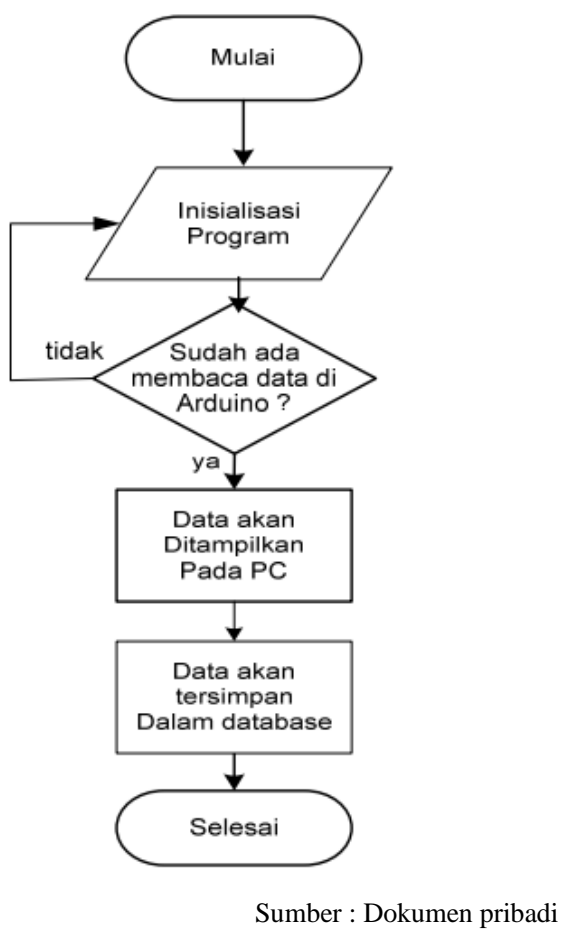

\section{Gambar 5. Diagram Alir Monitoring Getaran Secara Online}

Pemantauan getaran secara online pada sistem ini menggunakan web server. Sistem antar muka yang digunakan berbasis website. Pengguna harus melakukan login sesuai dengan akun yang sudah didaftarkan. Sistem login ini bertujuan agar data yang dikirim pengguna bersifat rahasia dan hanya pengguna saja yang bisa melakukan akses data. Pengguna dapat mengatur jumlah data yang akan tersimpan didatabase. Rancangan tampilan antar muka saat pengguna login dan sesudah login terlihat seperti pada gambar 6 dan gambar 7 dibawah ini.

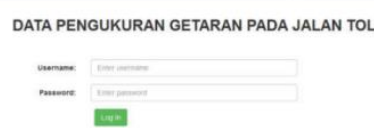

Sumber : Dokumen pribadi

\section{Gambar 6. Rancangan Tampilan Login Pada Web Server}

Pada saat login pengguna cukup memasukkan username dan password yang telah didaftarkan untuk mengakses data 
yang telah direkam selama pengujian. Apabila username atau password yang dimasukkan tidak sesuai dengan yang telah ditulis diprogram atau belum terdaftar maka pengguna tidak dapat mengakses web tersebut.

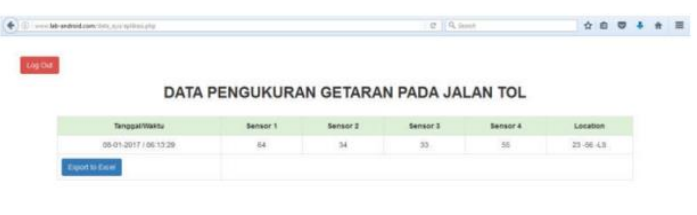

Sumber : Dokumen pribadi

\section{Gambar 7. Rancangan Tampilan Data Pengukuran}

\section{HASIL DAN PEMBAHASAN}

Sebelum sistem digunakan maka akan dilakukan pengujian terlebih dahulu, untuk mengetahui apakah sistem yang telah dirancang dapat bekerja dengan baik. Selanjutnya pengujian terhadap selisih pembacaan pengukuran antar masingmasing sensor, dan kemudian dilakukan pengambilan data yang dilakukan selama 2 hari.

\section{Pengujian Sensor}

Tahap awal pengujian sistem adalah melakukan karakterisasi sensor accelerometer dengan menghubungkan sensor tersebut dengan mikrokontroler Arduino Uno. Sensor accelerometer diuji ketika dalam kondisi diam dan pada saat ada pergerakan. Keluaran sensor dalam bentuk tegangan dengan satuan $\mathrm{mV}$ dan percepatan gravitasi $\mathrm{g}$ dengan satuan $\mathrm{m} /$. Sensor tersebut diatur dengan sensitivitas $1,5 \mathrm{~g}$. Keluaran sensor accelerometer dalam bentuk tegangan saja yang digunakan dalam sistem yang dirancang. Setiap kenaikan $1 \mathrm{~g}$ pada sensor accelerometer akan mengalami perubahan sekitar $200 \mathrm{mV}$ yang sesuai dengan datasheet sensor yang digunakan yaitu 206 $\mathrm{mV} / 1 \mathrm{~g}$ pada sensitivitas $6 \mathrm{~g}$ dan kenaikan 800 $\mathrm{mV} / \mathrm{g}$ pada sensitivitas $1.5 \mathrm{~g}$. Sebelum sensor digunakan untuk pengujian dilapangan maka sensor diuji dahulu dengan menghubungkan sensor dengan aruino UNO kemudian dijalankan sebuah program untuk mengetahui percepatan gravitasi dan tegangan keluaran dalam $\mathrm{mV}$ pada sumbu $\mathrm{x}, \mathrm{y}$, dan $\mathrm{z}$ pada posisi horizontal.

Pengambilan data pada masing-masing sensor dilakukan selama beberapa menit untuk mendapatkan data hasil pengukuran pada saat alat tidak menerima informasi getaran (kondisi diam). Dari data yang diperoleh diambil 25 sampel data untuk dianalisa. Keluaran dari accelerometer yang diuji adalah nilai tegangan dari sumbu $\mathrm{Z}(\mathrm{mV})$ dan nilai percepatan gravitasi $\left(\mathrm{m} / \mathrm{s}^{2}\right)$. Rata-rata besarnya nilai keluaran dari pengujian ditunjukkan pada data Tabel 1 berikut ini. Nilai rata-rata dari sensor pada kondisi diam ini akan digunakan sebagai acuan besarnya perubahan nilai percepatan gravitasi dan tegangan keluaran pada pegambilan data dijalan tol pada maisngmasing sensor

Tabel 1. Rata-rata Hasil Pengujian Kondisi Diam pada Masing-masing Sensor

\begin{tabular}{lcccc}
\hline Parameter & \multicolumn{4}{c}{ Rata-rata nilai keluaran pada Sensor } \\
& 1 & 2 & 3 & 4 \\
\hline Sumbu $Z$ & $769,20 \mathrm{mV}$ & $766,28 \mathrm{mV}$ & $770,84 \mathrm{mV}$ & $769,64 \mathrm{mV}$ \\
& & & & \\
$\begin{array}{l}\text { Percepatan } \\
\text { Gravitasi }\end{array}$ & $10,06 \mathrm{~m} / \mathrm{s}^{2}$. & $9,93 \mathrm{~m} / \mathrm{s}^{2}$. & $10,10 \mathrm{~m} / \mathrm{s}^{2}$ & $10,042 \mathrm{~m} / \mathrm{s}^{2}$. \\
& & & &
\end{tabular}

\section{Pengujian Kemirirngan}

Sensor Sebelum melakukan pengujian di jalan tol maka dilakukan pengujian kemiringan sensor. Pengujian ini untuk mengetahui nilai perubahan pada sumbu $\mathrm{Z}$ terhadap sudut kemiringan. Berikut adalah tabel hasil pengujian kemiringan sensor.

Tabel 2. Data Hasil Pengujian Kemiringan Sensor

\begin{tabular}{ccccc}
\hline Sudut $\theta$ & Sensor & Sensor & Sensor & Sensor \\
& 1 & 2 & 3 & 4 \\
\hline $0^{\circ}$ & 9.7 & 9.73 & 9.79 & 9.8 \\
$15^{\circ}$ & 9.21 & 9.3 & 9.33 & 9.2 \\
$30^{\circ}$ & 8.33 & 8.39 & 8.29 & 8.3 \\
$45^{\circ}$ & 7.15 & 7.21 & 7.19 & 7.19 \\
$60^{\circ}$ & 5.1 & 5.2 & 4.9 & 5.12 \\
$75^{\circ}$ & 3.14 & 3.1 & 3.2 & 3.11 \\
$90^{\circ}$ & 0.2 & 0.19 & 0.33 & 0.2 \\
\hline
\end{tabular}

Pengambilan Data Pada Jalan Tol

Data hasil pengukuran getaran pada jalan tol mengalami perubahan pada besarnya nilai tegangan keluaran pada sumbu $\mathrm{z}$ dan 
gravitasinya. Nilai dari sumbu $\mathrm{z}$ dan g pada pengukuran ini akan dikurangi dengan rata-rata pembacaan sensor dari pengujian pada kondisi diam sebelumnya sehingga dapat diketahui selisih pembacaan antara kondisi diam dan saat pengujian di pinggir tol. Berikut dibawah ini adalah data perbandingan dari masing-masing sensor antara nilai pada pengujian diam dan pengujian di jalan tol

Tabel 3. Perbandingan Rata-rata Nilai Percepatan Gravitasi pada Kondisi Diam dengan Pengujian di Jalan Tol

\begin{tabular}{lcccc}
\hline Pengujian & \multicolumn{4}{c}{ Rata-rata nilai keluaran pada Sensor } \\
& 1 & 2 & 3 & 4 \\
\hline Kondisi Diam & $10,06 \mathrm{~m} / \mathrm{s}^{2}$. & $9,93 \mathrm{~m} / \mathrm{s}^{2}$. & $10,10 \mathrm{~m} / \mathrm{s}^{2}$ & $10,04 \mathrm{~m} / \mathrm{s}^{2}$. \\
& & & & \\
di jalan tol & $9.78 \mathrm{~m} / \mathrm{s}^{2}$. & $10.12 \mathrm{~m} / \mathrm{s}^{2}$. & $10.35 \mathrm{~m} / \mathrm{s}^{2}$. & $10.16 \mathrm{~m} / \mathrm{s}^{2}$.
\end{tabular}

Pada Tabel 3 merupakan rata-rata nilai percepatan gravitasi pada pengujian kondisi diam, dan data pengambilan di jalan tol. Data tersebut untuk mengetahui besarnya nilai simpangan atau selisih pembacaan sensor pada saat pengujian dalam kondisi diam dan pada saat pengujian di jalan tol. Data hasil pengujian dijalan tol yang dianalisa diatas adalah data yang berhasil dikirim ke web server selama 30 menit (terdapat sebanyak 362 data). Pada Gambar 8 s/d Gambar 11 adalah grafik perubahan percepatan gravitasi pada g pada saat pengujian di jalan tol. Grafik tersebut merupakan hubungan antara waktu dan g pada masing-masing sensor.

Nilai $\mathrm{x}$ adalah nilai perubahan percepatan getaran yang terjadi, dimana hasil dari pengukuran di jalan tol dikurangi nilai percepatan masing-masing sensor pada pengujian kondisi diam. Dapat dianalisa dari data hasil pengujian diatas, bahwa penunjukkan nilai dari sensor ketika dalam kondisi diam dan pada saat berada di jalan tol mengalami perubahan nilai gravitasi.

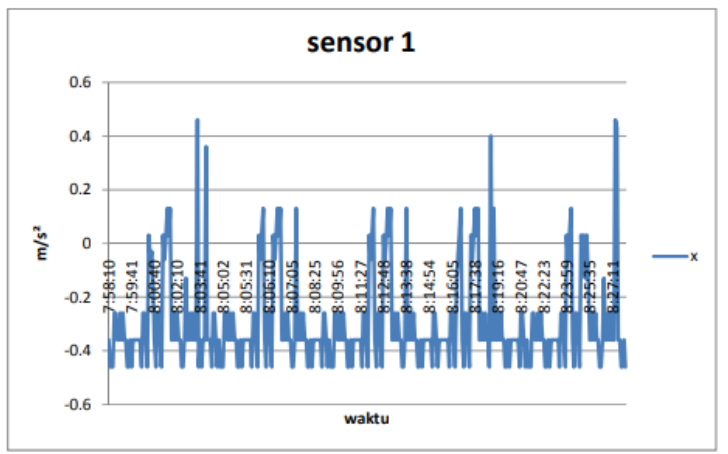

Gambar 8. Grafik Pengujian Sensor 1

Data yang berupa percepatan getaran pada sensor 1 dibandingkan dengan pengujian dalam kondisi diam sehingga diperoleh nilai perubahan gravitasi sebesar $-0,29$ $\mathrm{m} / \mathrm{s}^{2}$.

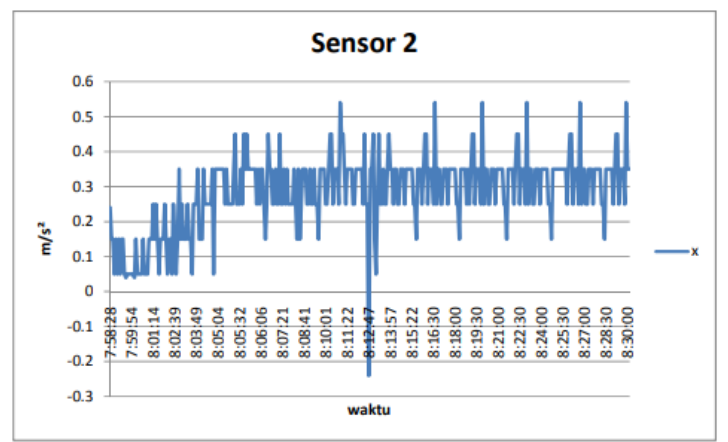

Gambar 9. Grafik Pengujian Sensor 2

Berdasarkan data hasil pengujian pada Gambar 9 diatas, bahwa penunjukkan nilai dari sensor ketika dalam kondisi diam dan pada saat berada di jalan tol mengalami perubahan nilai gravitasi. Nilai g rata-rata pada sensor 2 pada saat pengujian dijalan tol adalah sebesar $10,3 \mathrm{~m} / \mathrm{s}^{2}$. Sensor 2 berapa diposisi kedua setelah sensor 1 yaitu berada pada jarak 4 meter dari ruas jalan tol. Seperti yang terlihat diatas, nilai g mengalami perubahan rata-rata sebesar $0,28 \mathrm{~m} / \mathrm{s}^{2}$. 


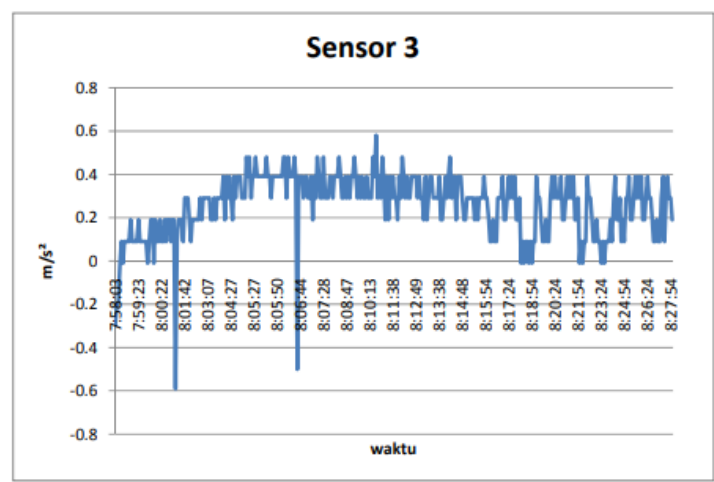

Gambar 10. Grafik Pengujian Sensor 3

Nilai g rata-rata pada sensor 3 pada saat pengujian dijalan tol adalah sebesar 10,3 $\mathrm{m} / \mathrm{s}^{2}$. Sensor 3 berapa diposisi kedua setelah sensor 1 yaitu berada pada jarak 7 meter dari ruas jalan tol. Seperti yang terlihat diatas, nilai $\mathrm{g}$ mengalami perubahan rata-rata sebesar $0,25 \mathrm{~m} / \mathrm{s}^{2}$.

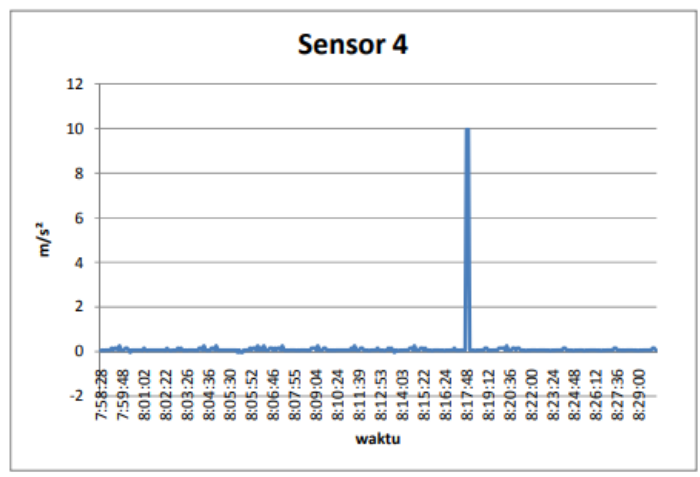

\section{Gambar 11. Grafik Pengujian Sensor 4}

Sensor 4 accelerometer ini berada diposisi keempat setelah sensor 3 yaitu pada jarak 10 meter dari ruas jalan tol $\mathrm{d}$ an merupakan sensor terjauh dari luar ruas jalan tol. Seperti yang terlihat diatas, nilai $\mathrm{g}$ mengalami perubahan rata-rata sebesar $0,12 \mathrm{~m} / \mathrm{s}^{2}$.

Berdasarkan dari data pengujian yang telah dianalisa diatas maka didapatkan ratarata nilai perubahan percepatan gravitasi dari masingmasing sensor dengan jarak yang sudah ditentukan adalah sebagai berikut :
Tabel 4. Rata-rata Perubahan Nilai Gravitasi Masing-masing Sensor

\begin{tabular}{|c|c|}
\hline Sensor & Perubahan gravitasi $\mathbf{( m / \mathbf { s } ^ { \mathbf { } } )}$ \\
\hline Sensor 1 & $-0,29$ \\
\hline Sensor 2 & 0,28 \\
\hline Sensor 3 & 0,25 \\
\hline Sensor 4 & 0,12 \\
\hline
\end{tabular}

Perubahan gravitasi yang terjadi pada masing-masing sensor berdasarkan pengujian yang telah dilakukan relatif kecil. Seperti pada standard tingkatan getaran bagi kesehatan yang diijinkan Tabel 5.

Tabel 5. Tingkat Resiko Terhadap Paparan Getaran (ISO 2631-1)

\begin{tabular}{|c||c||l|}
\hline $\begin{array}{c}\text { Tingkat } \\
\text { Resiko }\end{array}$ & $\begin{array}{c}\text { Nilai } \\
\text { percepatan } \\
\text { getaran } \\
\left(\mathbf{m} / \mathbf{s}^{2}\right)\end{array}$ & \multicolumn{1}{|c|}{ Keterangan } \\
\hline Rendah & $<0,45$ & $\begin{array}{l}\text { Paparan getaran masih di bawah zona } \\
\text { "Health Guidance Caution Zone } \\
\text { (HGCV)". Kasus penyakit belum } \\
\text { pernah ditemui pada nilai percepatan } \\
\text { getaran ini. }\end{array}$ \\
\hline \hline Sedang & $0,45-0,90$ & $\begin{array}{l}\text { Paparan getaran berada di zona HGCV. } \\
\text { Terdapat potensi resiko kesehatan. }\end{array}$ \\
\hline \hline Tinggi & $>0,90$ & $\begin{array}{l}\text { Paparan getaran berada di atas zona } \\
\text { HGCV. Resiko kesehatan sering terjadi } \\
\text { pada tingkat ini. }\end{array}$ \\
\hline
\end{tabular}

Berdasarkan Tabel 2 mengenai tingkat resiko terhadap paparan getaran bagi kesehatan, maka dapat disimpulkan bahwa dari hasil pengujian dari masing-masing sensor dengan jarak yang berbeda semuanya masuk ke dalam kategori rendah [6] yaitu $<0,45 \mathrm{~m} / \mathrm{s}^{2}$. Pengujian sensor 1 diperoleh hasil rata-rata dari simpangannya sebesar $-0,37 \mathrm{~m} / \mathrm{s}^{2}$, pada sensor 2 sebesar $0,16 \mathrm{~m} / \mathrm{s}^{2}$, sensor 3 sebesar $0,11 \mathrm{~m} / \mathrm{s}^{2}$, dan sensor 4 sebesar $0,07 \mathrm{~m} / \mathrm{s}^{2}$.

\section{SIMPULAN}

Berdasarkan hasil penelitian maka telah berhasil dibuat alat pengukur getaran yang menggunakan modul WiFi ESP8266 sehingga pemantauan getaran dapat dilakukan secara online. Hasil pengukuran terhadap getaran kendaraan yang melintas di jalan tol Jakarta-Serpong $\mathrm{Km} \quad 11$ 
menunjukkan nilai percepatan yang dihasilkan adalah $<0,45 \mathrm{~m} / \mathrm{s}^{2}$. Berdasarkan tingkat resiko terhadap paparan getaran bagi kesehatan nilai percepatan tersebut berada dalam kategori rendah sehingga jarak jalur tol berada pada zona aman bagi kesehatan penduduk disekitar.

\section{DAFTAR PUSTAKA}

[1] Kementerian Negara Pekerjaan Umum, Mitigasi Dampak Kebisingan Akibat Lalu Lintas Jalan. Departemen Pekerjaan Umum. Jakarta, 2005.

[2] K. N. L. Hidup., Keputusan Menteri Negara Lingkungan Hidup. 1996.

[3] K. Wardika, I. G. P. Suparsa, and D. M. Priyantha, "Analisis Kebisingan Lalu Lintas Pada Ruas Jalan Arteri (Studi Kasus Jalan Prof. Dr. IB. Mantra Pada KM 15 s/d KM 16)," J. Ilm. Elektron. Infrastruktur Tek. Sipil, no. 15, pp. 1-8, 2010.
[4] E. K. Wati and F. Anangga, "Rancang Bangun Sistem Pemantauan Getaran Kereta Rel Listrik Commuter Line Secara Online," J. Teknol. Kedirgant., vol. 5, no. 1, 2016.

[5] T. Arduino, D. Cuartielles, G. Martino, T. Igoe, D. Mellis, and M. Banzi, "The Making of Arduino How five friends engineered a small circuit board that' $\mathrm{s}$ taking the DIY world by storm Photo: Massimo Banzi The Arduino team contracted with a company that can," pp. 2-4, 2015.

[6] E. K. Wati, "Pengukuran Dan Analisis Kebisingan Permukiman Tepi Rel Kereta Listrik," STRING, vol. 4, no. 3, pp. 273-279, 2020. 